OPEN ACCESS

Edited by:

Ivan V. Litvinov

McGill University, Canada

Reviewed by:

Thilo Gambichler,

Ruhr-University Bochum, Germany

Serena Lembo,

University of Salerno, Italy

*Correspondence:

Masoud Dadash

m_d6512@yahoo.com

masoud.dadashi@sbmu.ac.ir

Specialty section This article was submitted to

Dermatology,

a section of the journal

Frontiers in Medicine

Received: 17 June 2020 Accepted: 07 September 2020

Published: 29 October 2020

Citation:

Sameni F, Hajikhani B, Yaslianifard S,

Goudarzi M, Owlia P, Nasiri MJ,

Shokouhi S, Bakhtiyari $M$ and Dadashi M (2020) COVID-19 and Skin Manifestations: An Overview of Case Reports/Case Series and Meta-Analysis of Prevalence Studies.

Front. Med. 7:573188.

doi: 10.3389/fmed.2020.573188

\section{COVID-19 and Skin Manifestations: An Overview of Case Reports/Case Series and Meta-Analysis of Prevalence Studies}

\author{
Fatemeh Sameni ${ }^{1}$, Bahareh Hajikhani ${ }^{2}$, Somayeh Yaslianifard ${ }^{3}$, Mehdi Goudarzi $^{2}$, \\ Parviz Owlia ${ }^{4}$, Mohammad Javad Nasiri ${ }^{2}$, Shervin Shokouhi ${ }^{5,6}$, Mahmood Bakhtiyari ${ }^{7,8}$ and \\ Masoud Dadashi ${ }^{3,7 *}$ \\ ${ }^{1}$ Department of Microbiology, Faculty of Medicine, Shahed University, Tehran, Iran, ${ }^{2}$ Department of Microbiology, School of \\ Medicine, Shahid Beheshti University of Medical Sciences, Tehran, Iran, ${ }^{3}$ Department of Microbiology, School of Medicine, \\ Alborz University of Medical Sciences, Karaj, Iran, ${ }^{4}$ Molecular Microbiology Research Center, Shahed University, Tehran, Iran, \\ ${ }^{5}$ Infectious Diseases and Tropical Medicine Research Center, Shahid Beheshti University of Medical Sciences, Tehran, Iran, \\ ${ }^{6}$ Department of Infectious Diseases and Tropical Medicine, Loghman Hakim Hospital, Shahid Beheshti University of Medical \\ Sciences, Tehran, Iran, ${ }^{7}$ Non-communicable Diseases Research Center, Alborz University of Medical Sciences, Karaj, Iran, \\ ${ }^{8}$ Department of Community Medicine, Alborz University of Medical Sciences, Karaj, Iran
}

Background and Aim: Since the onset of the 2019-nCoV disease (COVID-19), many skin manifestations have been reported in COVID-19 patients. This study aims to provide a systematic review and meta-analysis of various skin manifestations among patients with COVID-19 through case reports/case series and prevalence studies.

Methods: A systematic literature search strategy was conducted by reviewing original research articles published in Medline, Web of Science, and Embase databases in 2020. Statistical analysis was performed using STATA software, version 14.0 (Stata Corporation, College Station, Texas, USA) to report the global prevalence of skin manifestations among patients with COVID-19.

Results: Forty-three studies (35 articles were case reports/case series, and 8 articles were prevalence studies) were included in our study. A meta-analysis of prevalence studies showed that skin manifestations among patients with COVID-19 were reported in four countries (China, Thailand, France, and Italy), with an overall prevalence of $1.0 \%$ [(95\% Cl) $0.1-1.9]$ among 2,621 patients. Evaluation of the results of the case reports/case series revealed that, out of 54 patients with COVID-19, 48 patients (88.8\%) showed skin manifestations. Erythematous rash (59.1\%) and urticaria (14.8\%) were the most common skin manifestation reported in studied patients.

Conclusion: Infection with 2019-nCoV may lead to skin manifestations with various clinical symptoms. These clinical features combined with clinical symptoms of COVID-19 may aid in the timely diagnosis of patients with COVID-19.

Keywords: coronavirus, 2019-nCoV, COVID-19, skin manifestations, meta-analysis 


\section{INTRODUCTION}

The first reports of people infected with 2019 novel coronavirus (2019-nCoV) were published in December 2019 in Wuhan, China. Afterwards, the pandemic spread rapidly across the world (1-3). The symptoms of 2019-nCoV disease (COVID-19) vary from person to person, and it covers a wide range of clinical manifestations (4). However, most of the patients presented mild or no symptoms (5-7). Older people and those who suffer from underlying medical conditions such as high blood pressure, heart disease, or diabetes seem to be at higher risk for developing more serious complications of COVID-19 (8). According to studies, the most common symptoms of COVID-19 are fever, tiredness, and dry cough. Also, some patients may experience muscle pains, runny or stuffy nose, sore throat, gastrointestinal symptoms, and loss of smell and taste (9-11). In addition to these symptoms and according to the results of studies on COVID19 patients, different types of skin manifestations have been seen in a number of patients $(12,13)$. The skin involvement in patients with COVID-19 was not noticed at the early stages of this pandemic, but it has received much more attention recently (14). The most important skin manifestations in people with COVID-19 are red spots on the hands, blisters on the trunk, and itchy hives (14). In some COVID-19 patients, red patches of itchy skin, associated with skin inflammation, have been observed as well. These lesions affect the hands and feet and may look like small, swollen, itchy blisters (15). Despite the observation of skin manifestations in patients with COVID19 , researchers are still looking for answers to the question of whether this skin presentations are directly related to the virus itself or are complications of the infection (16). In addition, in many cases, skin problems in COVID-19 patients may be due to drug side effects and the virus may not be the cause $(17,18)$. Therefore, it seems that finding out the potential relationship between COVID-19 and skin manifestations can assist in better understanding the pathogenesis of the disease and adoption of better infection control policies. The present study aimed to investigate the distribution, types, and the most prevalent skin manifestations among patients with COVID-19 based on case reports/case series and prevalence studies around the world.

\section{METHODS}

\section{Search Strategy}

A broad systematic literature review was conducted via reviewing original research articles published in Medline, Web of Science, and Embase databases in 2020. The following phrases were used in the search strategy of this article: COVID OR COVID-19 OR novel coronavirus OR new coronavirus OR coronavirus 2019 OR 2019-nCoV OR nCoV OR CoV-2 OR SARS-2 OR SARS$\mathrm{CoV}-2 \mathrm{OR}$ severe acute respiratory syndrome coronavirus $2 \mathrm{OR}$ skin manifestation OR cutaneous manifestation OR urticaria OR exanthem OR rash OR livedo reticularis OR eczema OR skin OR cutaneous OR skin disease OR dermal disease OR skin lesion. In order to identify further studies, bibliographies of related articles were also screened.

\section{Inclusion and Exclusion Criteria}

We evaluated all case reports/case series and prevalence studies that were about the prevalence of skin manifestations among patients with COVID-19. These studies reported sufficient data for analysis, including country of origin, the number of patients with COVID-19, number of patients with skin manifestations, type of skin manifestations, clinical symptoms, laboratory findings, outcomes, diagnostic methods, and treatment. Titles, abstracts, and full texts of the recorded studies were evaluated based on the inclusion and exclusion criteria. The exclusion criteria were as follows: (1) animal research only, (2) studies considering skin manifestation only, (3) studies considering patients with COVID-19 only, (4) review articles, (5) abstracts presented in conferences, and (6) duplicate studies. Appropriate papers were selected by $\mathrm{BH}$ and $\mathrm{MG}$ after evaluating all studies based on the inclusion and exclusion criteria.

\section{Data Extraction and Definitions}

The following items were considered in each study: the last name of the first author, study time, time of publication, country, number of patients with COVID-19, number of patients with skin manifestations, type of skin manifestations, clinical symptoms, laboratory findings, outcomes, diagnostic methods, and treatment. Two independent individuals collected the data and another researcher confirmed them.

\section{Meta-Analysis}

Statistical analysis was performed using STATA software, version 14.0 (Stata Corporation, College Station, Texas, USA) to report the global prevalence of skin manifestations among patients with COVID-19. The fixed-effects (FEM) (19) and the randomeffects models (REM) were utilized for data collection. Statistical heterogeneity was assessed using the $Q$-test and the $I^{2}$ statistical methods. $P<0.05$ was regarded as statistically significant.

\section{RESULTS}

\section{Characteristics of Included Studies}

Overall, 189 citations were recorded in the initial database searches. Our data collection was from three databases and many duplicate studies were included. After removing 34 duplicates, 155 non-duplicate studies remained. Of these, 88 non-relevant studies were removed from our review after checking titles and abstracts. In the step of full-text screening, 24 irrelevant articles were also excluded. Eventually, 43 studies were selected for the final analysis (Figure 1).

\section{The Frequency of Skin Manifestations Among Patients With COVID-19 Based on Prevalence Studies}

Out of 43 articles that reported the prevalence of skin manifestations among patients with COVID-19, eight articles (four from Asia and four from Europe) were prevalence studies and 35 articles (six from Asia, 24 from Europe, four from America, and one from Africa) were case reports/case series (Tables 1, 2). A meta-analysis of prevalence studies showed that the frequency of skin manifestations among patients with 


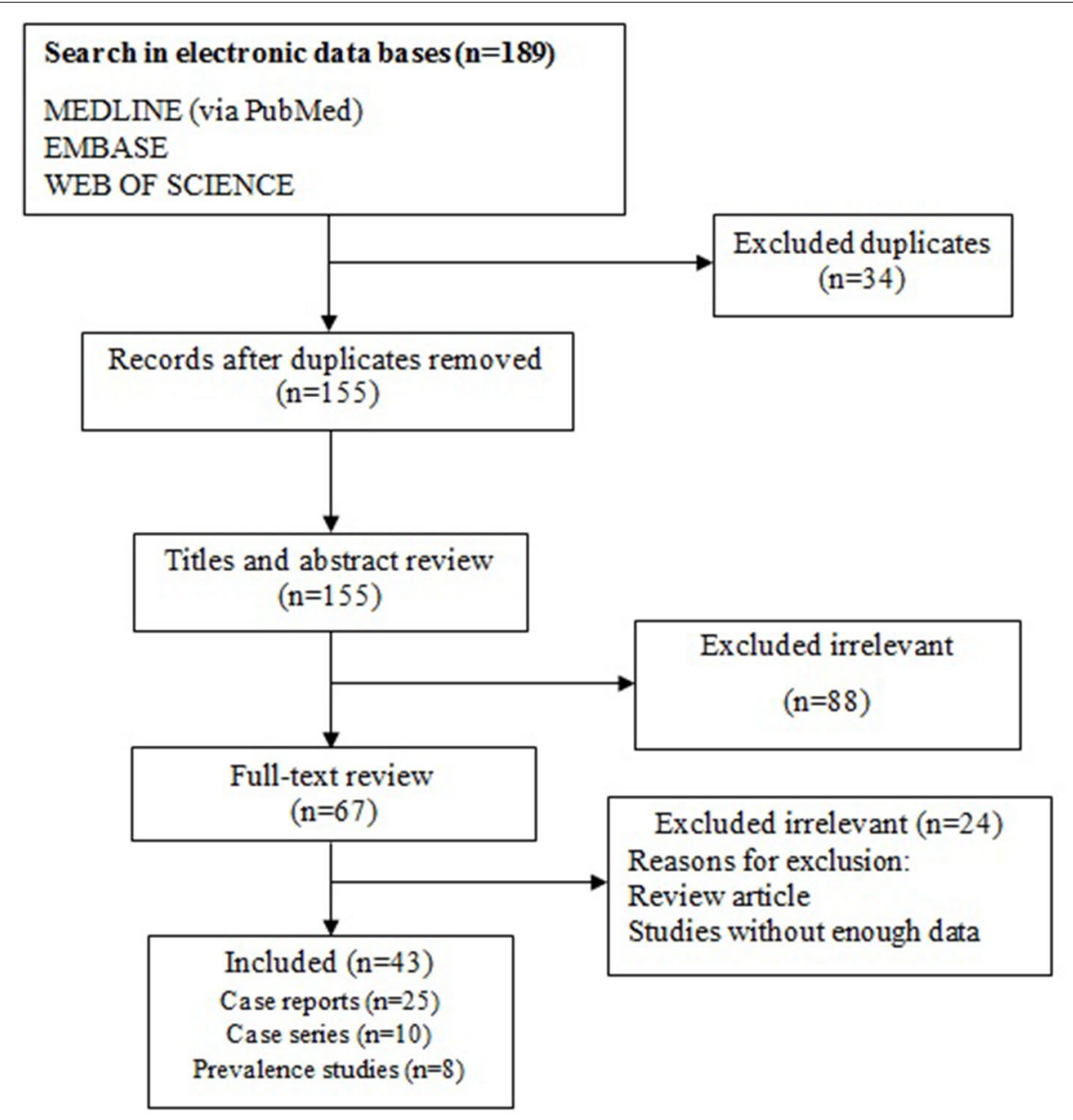

FIGURE 1 | Flow chart of study selection for inclusion in the systematic review.

TABLE 1 | Characteristics of included prevalence studies.

\begin{tabular}{|c|c|c|c|c|c|c|c|c|}
\hline First author & Country & Published time & $\begin{array}{l}\text { Type of } \\
\text { study }\end{array}$ & $\begin{array}{l}\text { Number of } \\
\text { patients } \\
\text { with } \\
\text { CoviD-19 }\end{array}$ & $\begin{array}{l}\text { Number of COVID-19 } \\
\text { patients with skin } \\
\text { manifestations }\end{array}$ & Mean age & $\begin{array}{l}\text { Male/ } \\
\text { female }\end{array}$ & $\begin{array}{l}\text { Diagnostic } \\
\text { method }\end{array}$ \\
\hline Bouaziz (20) & France & Apr-20 & Case series & 14 & 7 & $\mathrm{nr}$ & $\mathrm{nr}$ & PCR \\
\hline Joob (21) & Thailand & Jan-20 & Case series & 41 & 1 & 40.5 & $4 \mathrm{M} / 37 \mathrm{~F}$ & real-time PCR \\
\hline Joob (22) & Thailand & Mar-20 & Case series & 48 & 1 & $\mathrm{nr}$ & $\mathrm{nr}$ & RT-PCR \\
\hline Tammaro (23) & Italy & Apr-20 & Case series & 130 & 2 & $\mathrm{nr}$ & $\mathrm{nr}$ & RT-PCR \\
\hline Zhang (24) & China & Feb-20 & Case series & 140 & 2 & 57 & $71 \mathrm{M} / 69 \mathrm{~F}$ & RT-PCR \\
\hline Million (25) & France & May-20 & Case series & 1061 & 3 & 43.6 & 492M/569F & PCR \\
\hline Guan (26) & China & Feb-20 & Case series & 1099 & 2 & 47 & $639 \mathrm{M} / 460 \mathrm{~F}$ & RT-PCR \\
\hline
\end{tabular}

RT-PCR, Real time-Polymerase Chain Reaction; nr, not report.

COVID-19 were reported in four countries (China, Thailand, France, and Italy), with an overall frequency of $1.0 \%$ [(95\% CI) 0.1-1.9] among 2621 COVID-19 patients (Table 3). Figure 2 is a forest plot, which can summaries almost all of the necessary data of a meta-analysis. The heterogeneity among assessed articles is presented in Figure 3 (called a funnel plot, which is a plot 
TABLE 2 | Characteristics of Case reports/case series studies.

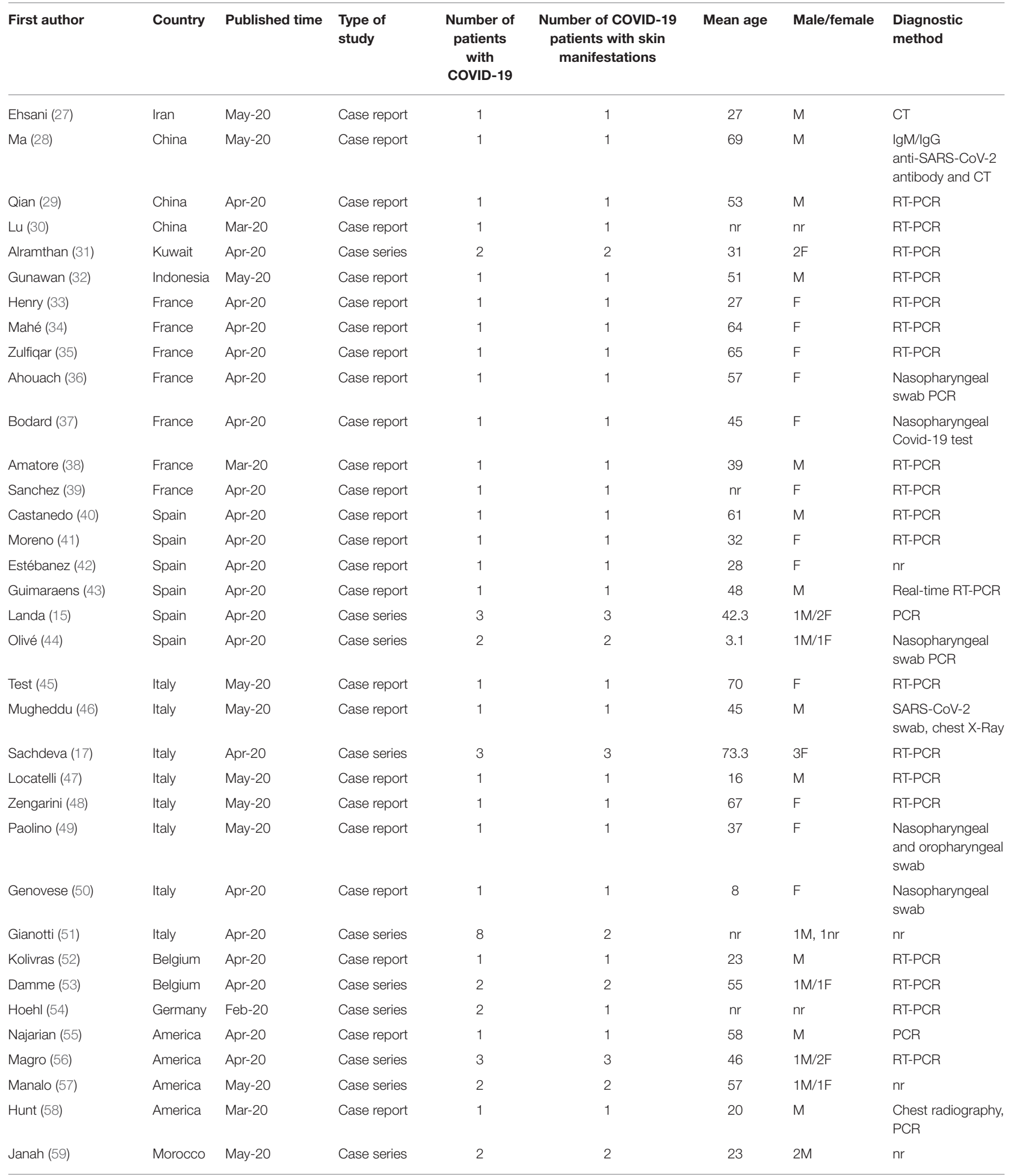

RT-PCR, Real time-Polymerase Chain Reaction; nr, not report. 
TABLE 3 | Frequency of skin manifestations among patients with COVID-19.

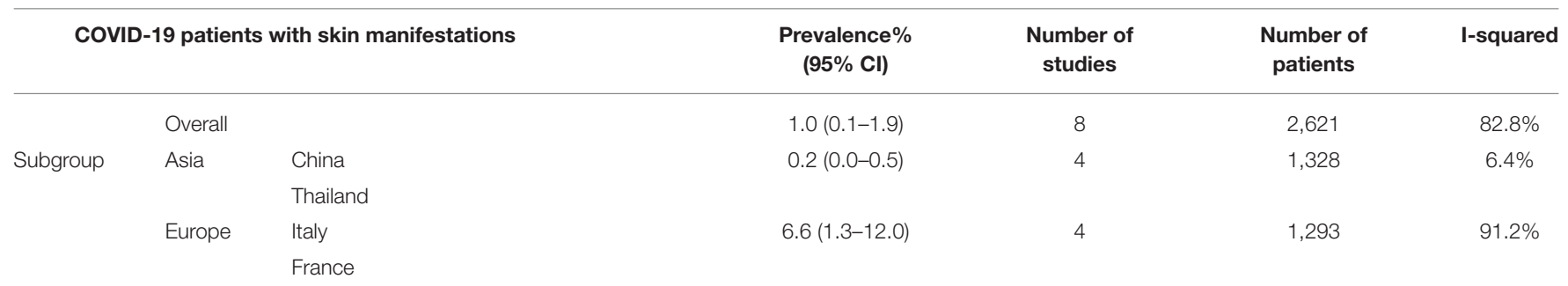

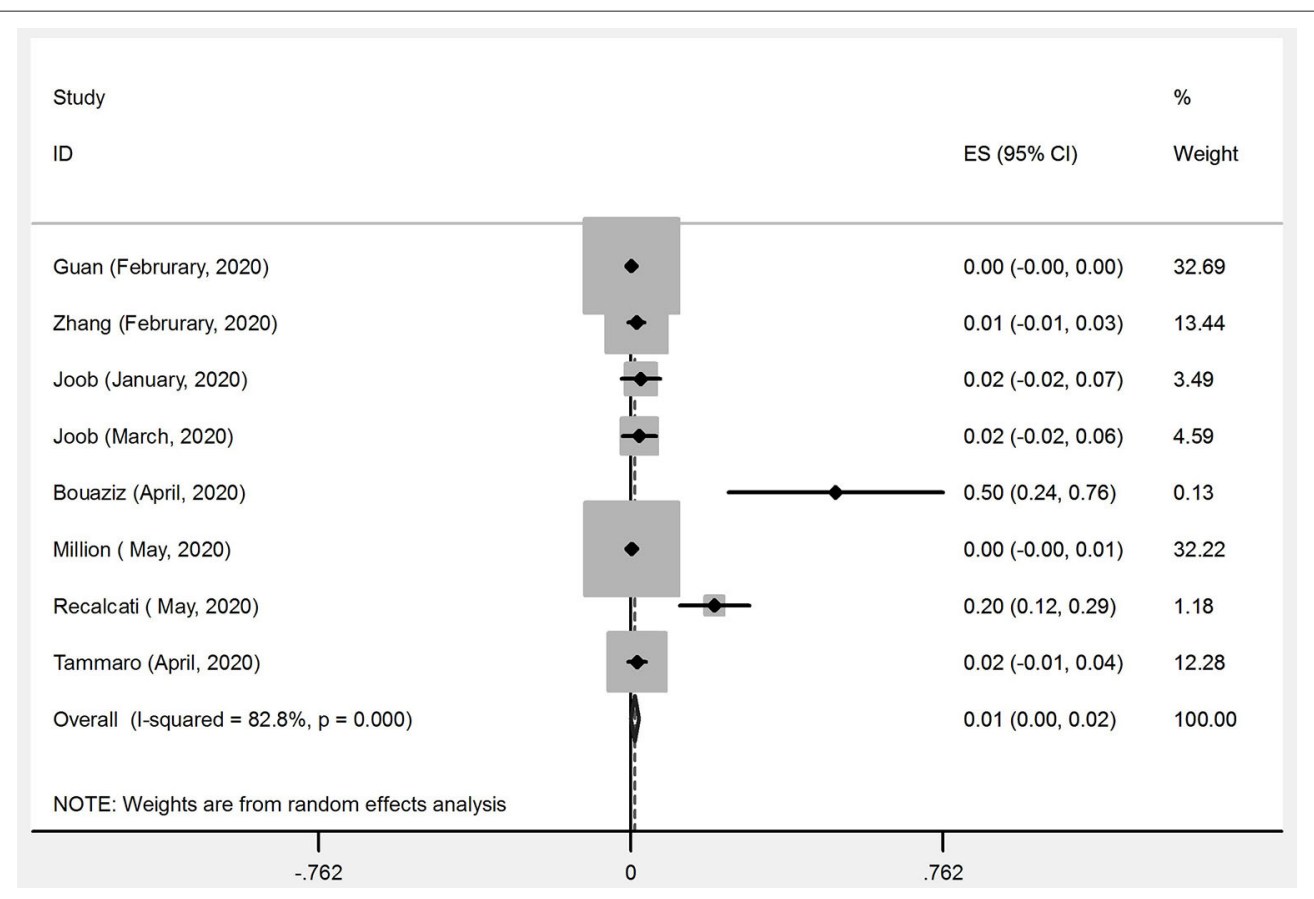

FIGURE 2 | Forest plot of the meta-analysis on the prevalence of skin manifestations among patients with COVID-19.

of the intervention effect estimates from individual studies against a measure of study size) and Figure 4 (called a galbraith plot for displaying several estimates of the same quantity that have different standard errors). The numbers and types of skin manifestations among COVID-19 patients were as follow: erythematous rash $(15 / 2,621)$, urticaria $(7 / 2,621)$, exanthema $(4 / 2,621)$, chickenpox like-vesicles $(3 / 2,621)$, petechia, purpura, chilblain like-lesion and herpetiform lesion (each $2 / 2,621$ ), and livedo and eruptive cherry angioma (each 1/2,621). Erythematous rash and urticaria were the most skin manifestations among patients with COVID-19.

\section{The Frequency of Skin Manifestations Among Patients With COVID-19 Among Different Continents Based on Prevalence Studies}

The meta-analysis of prevalence studies showed that the frequency of skin manifestations among patients with COVID-19 was $6.6 \%$ (95\% CI 1.3-12.0) among 1,293 patients in Europe, and
0.2\% (95\% CI 0.0-0.5) among 1,328 patients in Asia (Table 3). There has been no report of skin manifestations among COVID19 patients from America, Africa, and Oceania. As shown in Table 1, the most COVID-19 patients with skin manifestations were reported in Europe (Italy and France with 20 and 10 cases, respectively). Also, the most types of skin manifestations in Italy, France, China, and Thailand were erythematous rash, exanthema, petechiae, and chronic urticaria, respectively.

\section{The Frequency of Skin Manifestations Among Patients With COVID-19 Based on Case Reports/Case Series}

We assessed the skin manifestations among cases with COVID19 that were reported in the mentioned electronic databases. Characteristics of case reports/case series studies (which were not taken into account during the analyses already mentioned above) are shown in Table 2.

According to the results of the case reports/case series, 30 types of skin manifestations have been reported among patients 


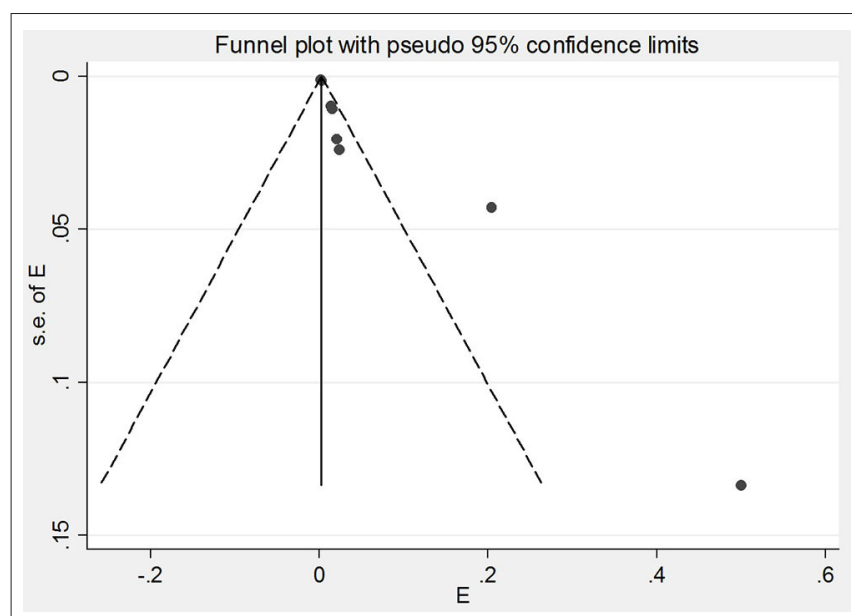

FIGURE 3 | Funnel plot of the meta-analysis on the prevalence of skin manifestations among patients with COVID-19.

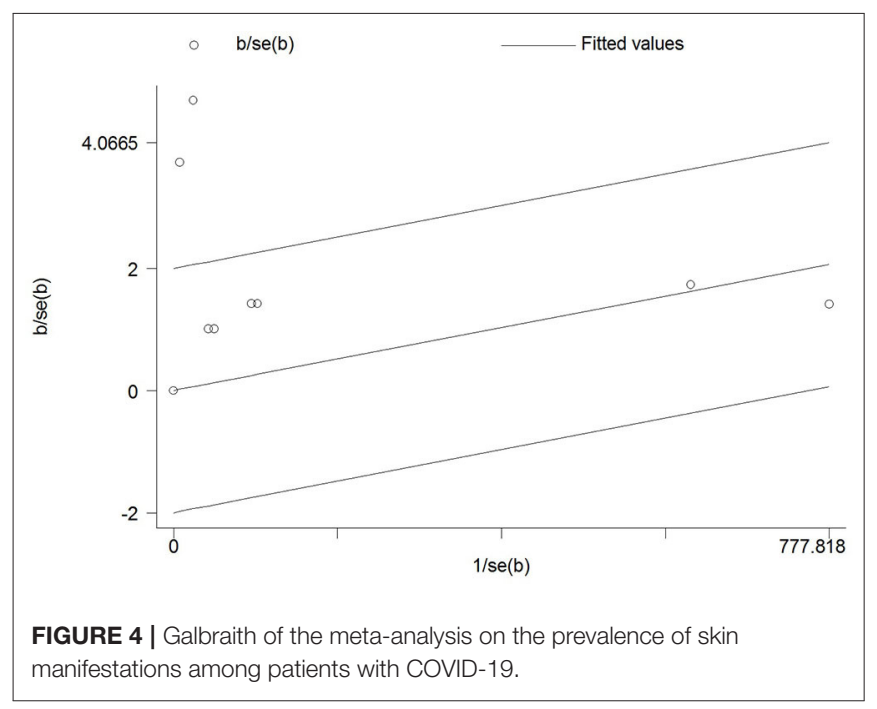

with COVID-19 from 11 countries (Table 4). Most of the cases were in Italy (11 cases), Spain (nine cases), France (seven cases), and the United States (six cases) (Table 4). Among the patients whose gender was mentioned, 24 patients with skin manifestations were women, and 20 were men. Evaluation of the results of the studied articles demonstrated that out of 54 patients with COVID-19, 48 patients (88.8\%) showed skin manifestations. In the field of skin manifestations types, erythematous rash (32 studies), pruritic plaques (13 studies), urticaria (eight studies), and macule (seven studies) were the most reported presentations in included studies (Table 4). Among these, erythematous rash (59.1\%) and urticaria $(14.8 \%)$ were the most common skin manifestations reported in patients with COVID-19.

The clinical symptoms were also checked in COVID-19 patients with skin manifestations. According to the results of the studies, 35 types of clinical symptoms were reported in these patients (Table 4). Of these, fever (50.0\%), cough (35.1\%), dyspnea and respiratory problems ( $12.9 \%$ each), and diarrhea and headache ( $11.1 \%$ each) were the most common clinical symptoms among COVID-19 patients with skin manifestations.

Of the 14 types of comorbidities registered in the studies, diabetes (4), obesity and hypertension (three studies for each), and chronic renal failure (2) were the most common comorbidities (Table 4). Accordingly, obesity and diabetes (7.4\%) and hypertension (5.5\%) were the most common comorbidities reported in patients with COVID-19 with skin manifestations.

In 25 articles, CT scan was mentioned as one of the diagnostic methods used for COVID-19. The results of patients' CT scan were as follows: Ground-glass opacification, bilateral abnormalities, atypical bilateral pneumonia, and normal. Bilateral abnormalities were reported in 10 studies and in 12 (22.2\%) patients (Table 4). The results of CTs in most of the evaluated patients were of this type. Laboratory examination of patients showed that elevated C-reactive protein (CRP) (in six studies) and thrombocytopenia (in four studies) were the most common findings (Table 4). These two laboratory findings were in $12.9 \%(7 / 54)$ and $7.4 \%(4 / 54)$ of patients, respectively. The study also looked at the patients' outcomes. According to the analyzed studies, of the 48 patients (mentioned in Table 2), 44 patients returned to life and one died (Table 4). The patient with COVID-19 who died was a 71-year-old man who had acute urticaria. A patient with clinical symptoms (weakness, pyrexia, hypoxemia, pain, constipation, chest pain, and tachycardia) and commodities (type 2 diabetes, hypertension, peripheral artery disease, and chronic renal failure) was reported by Damme in April 2020 (53).

In the case reports/case series studies, the drugs used for treatment of COVID-19 patients with skin manifestations were classified into three sections: antiviral drugs, antibacterial drugs, and a combination of drugs (Table 5). Lopinavir and Ritonavir were the most widely used antiviral drugs (four studies for each) for the treatment of patients. Among the antibacterial drugs listed in Table 5, azithromycin was the most widely used antibacterial agent that was used in six studies. Ceftriaxone and omeprazole were other antibiotics used in two studies to treat patients. Various studies have used different treatment regimens to treat COVID-19 patients. One treatment regimen including Hydroxychloroquine (HCQ) and azithromycin has been used in two studies and other therapies have been reported just in one study. Other drug combinations in addition to antiviral and antibacterial drugs are shown in Table 5 as "others." As it turns out, HCQ (in 10 studies), Paracetamol (in four studies), and Prednisone (in two studies) were other drug combinations that were used more than others in the treatment of patients.

\section{DISCUSSION}

The 2019-nCoV, which causes the COVID-19 pandemic in the world, has infected more than two million people worldwide and caused many deaths in various countries (60). It is therefore a serious threat to human life around the world. Despite valuable and numerous researches having been conducted on this virus, there are still many ambiguities to fully identify its behavior 
TABLE 4 | Summary of the case reports/case series findings.

\begin{tabular}{|c|c|c|c|c|}
\hline \multicolumn{5}{|c|}{ Overall } \\
\hline Types of study & Number of studies & $\begin{array}{l}\text { Total patients with } \\
\text { COVID-19 }\end{array}$ & $\begin{array}{l}\text { Total COVID-19 patients } \\
\text { with skin manifestations }\end{array}$ & $n / N^{*}(\%)$ \\
\hline Case report & 25 & 25 & 25 & $25 / 25(100.0)$ \\
\hline \multirow[t]{2}{*}{ Case series } & 10 & 29 & 23 & 23/29 (79.3) \\
\hline & Variables & Number of studies & $\begin{array}{l}\text { Number of patients with } \\
\text { skin manifestations }\end{array}$ & $n / N^{*}(\%)$ \\
\hline \multirow{30}{*}{$\begin{array}{l}\text { Types of skin } \\
\text { manifestations }\end{array}$} & Eruption & 1 & 1 & $1 / 54(1.8)$ \\
\hline & Pustule & 1 & 1 & 1/54 (1.8) \\
\hline & Scales & 4 & 4 & $4 / 54(7.4)$ \\
\hline & Erythematous & 19 & 19 & $19 / 54(35.1)$ \\
\hline & Papule & 4 & 4 & 4/54 (7.4) \\
\hline & Plaques & 7 & 7 & 7/54 (12.9) \\
\hline & Pruritic & 6 & 6 & 6/54 (11.1) \\
\hline & Rash & 13 & 13 & $13 / 47(24.0)$ \\
\hline & Petechia & 2 & 2 & 2/54 (3.7) \\
\hline & Maculopapula & 4 & 4 & 4/54 (7.4) \\
\hline & Macule & 7 & 7 & 7/54 (12.9) \\
\hline & Patches & 4 & 4 & 4/54 (7.4) \\
\hline & Urticaria & 8 & 9 & 9/54 (16.6) \\
\hline & Edematous & 2 & 2 & 2/54 (3.7) \\
\hline & Itchy & 5 & 5 & 5/54 (9.2) \\
\hline & Lesions & 5 & 8 & 8/54 (14.8) \\
\hline & Squamous & 1 & 1 & $1 / 54(1.8)$ \\
\hline & Psoriasis & 1 & 1 & $1 / 54(1.8)$ \\
\hline & Papulovesicular & 2 & 2 & 2/54 (3.7) \\
\hline & Erythematoedematous & 1 & 1 & $1 / 54(1.8)$ \\
\hline & Purpura & 4 & 5 & $5 / 54(9.2)$ \\
\hline & Exanthema & 1 & 1 & $1 / 54(1.8)$ \\
\hline & Livedo & 1 & 1 & $1 / 54(1.8)$ \\
\hline & Cyanosis & 1 & 1 & $1 / 54(1.8)$ \\
\hline & Hemorrhage & 1 & 1 & 1/54 (1.8) \\
\hline & Pain & 2 & 2 & 2/54 (3.7) \\
\hline & Ulcer & 1 & 1 & 1/54 (1.8) \\
\hline & Papilla & 1 & 1 & 1/54 (1.8) \\
\hline & Vasculitis & 1 & 1 & $1 / 54(1.8)$ \\
\hline & Gangrene & 1 & 1 & 1/54 (1.8) \\
\hline \multirow{14}{*}{$\begin{array}{l}\text { Clinical } \\
\text { manifestation }\end{array}$} & Cough & 16 & 19 & $19 / 54(35.1)$ \\
\hline & Diarrhea & 6 & 6 & 6/54 (11.1) \\
\hline & Nasal congestion & 4 & 4 & $4 / 54(7.4)$ \\
\hline & Fatigue & 4 & 4 & $4 / 54(7.4)$ \\
\hline & Myalgia & 5 & 5 & 5/54 (9.2) \\
\hline & Arthralgia & 4 & 4 & 4/54 (7.4) \\
\hline & Fever & 21 & 27 & 27/54 (50.0) \\
\hline & Asthenia & 3 & 3 & 3/54 (5.5) \\
\hline & Anorexia & 1 & 1 & 1/54 (1.8) \\
\hline & Pain & 1 & 1 & $1 / 54(1.8)$ \\
\hline & Headache & 6 & 6 & 6/54 (11.1) \\
\hline & Malaise & 1 & 1 & 1/54 (1.8) \\
\hline & Sore throat & 2 & 2 & 2/54 (3.7) \\
\hline & Dyspnea & 2 & 7 & $7 / 54$ (12.9) \\
\hline
\end{tabular}


TABLE 4 | Continued

\section{Overall}

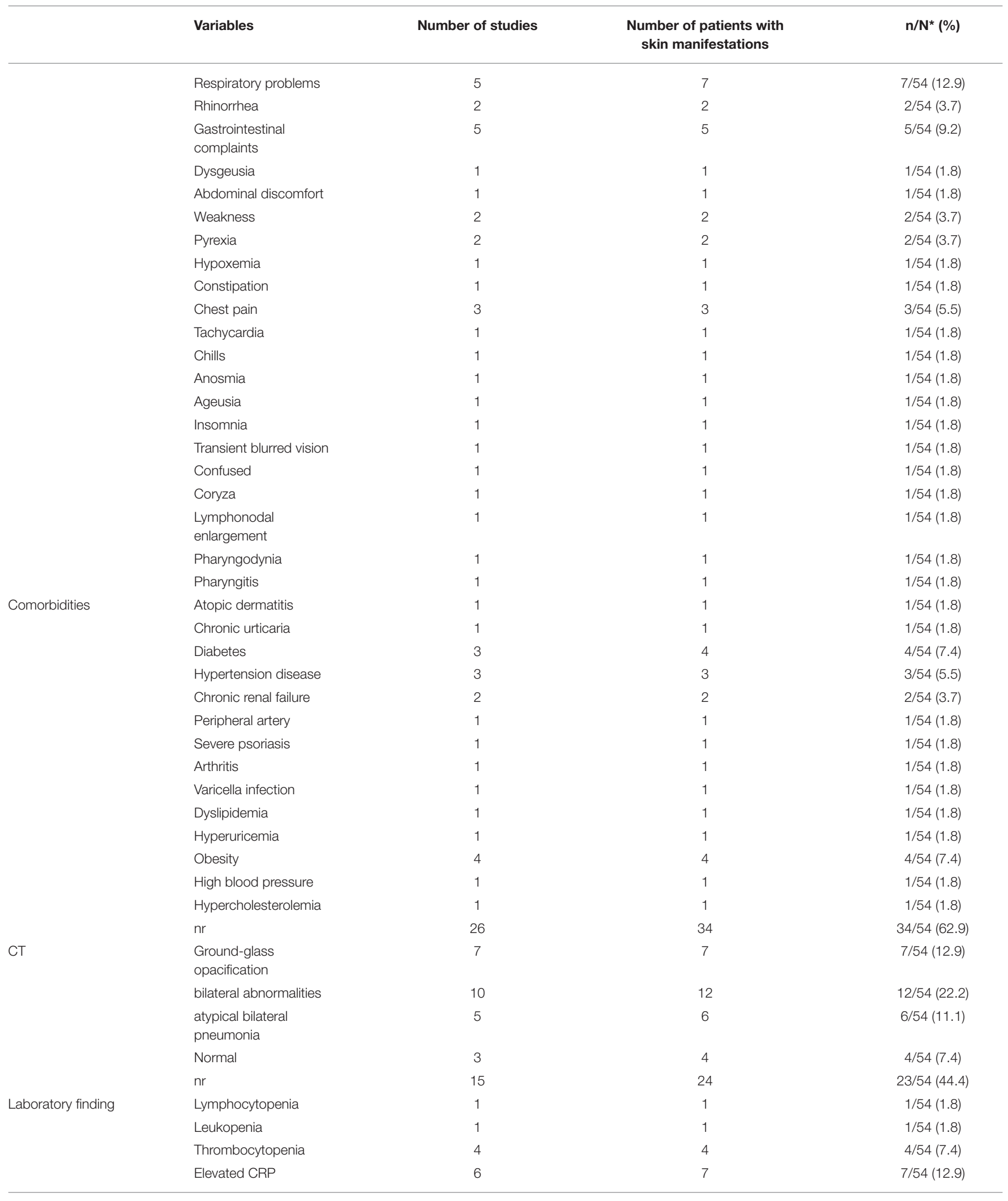

(Continued) 


\begin{tabular}{|c|c|c|c|c|}
\hline \multicolumn{5}{|c|}{ Overall } \\
\hline & Variables & Number of studies & $\begin{array}{l}\text { Number of patients with } \\
\text { skin manifestations }\end{array}$ & $n / N^{*}(\%)$ \\
\hline & Low hemoglobin & 1 & 1 & $1 / 54(1.8)$ \\
\hline & Low RBC & 1 & 1 & $1 / 54(1.8)$ \\
\hline & Low $\mathrm{HCO}_{3}$ & 1 & 1 & $1 / 54(1.8)$ \\
\hline & High ESR & 2 & 2 & 2/54 (3.7) \\
\hline & High WBC & 1 & 1 & 1/54 (1.8) \\
\hline & High LDH & 1 & 1 & $1 / 54(1.8)$ \\
\hline & Lymphopenia & 2 & 2 & 2/54 (3.7) \\
\hline & $\begin{array}{l}\text { Increased liver } \\
\text { enzymes (GOT, GPT, } \\
\text { LDH, GGT doubled) }\end{array}$ & 1 & 1 & $1 / 54(1.8)$ \\
\hline & Elevated INR & 1 & 1 & $1 / 54(1.8)$ \\
\hline & $\mathrm{nr}$ & 20 & 24 & $24 / 54(54.4)$ \\
\hline \multirow[t]{6}{*}{ Isolation source } & Nasopharyngeal swab & 18 & 21 & $21 / 54(38.8)$ \\
\hline & Nasal swab & 1 & 1 & 4/54 (7.4) \\
\hline & Oropharyngeal swabs & 4 & 4 & 4/54 (7.4) \\
\hline & Pharyngeal swab & 4 & 4 & $4 / 54(7.4)$ \\
\hline & Sputum & 1 & 1 & $1 / 54(1.8)$ \\
\hline & $\mathrm{nr}$ & 14 & 20 & $20 / 54(37.0)$ \\
\hline \multirow[t]{2}{*}{ Outcome } & Live & 33 & 44 & $44 / 54(81.4)$ \\
\hline & Death & 1 & 1 & $1 / 54(1.8)$ \\
\hline
\end{tabular}

${ }^{*} n$, number of patients with any variables; N, the total number of patients with COVID-19; nr, not report.

in human pathogenesis. One of the most important issues that can be learned in the future is the association of COVID19 with other infections. Similar to other RNA viruses, the 2019-nCoV infection can be associated with skin manifestations $(14,38)$. Recently, evidence of various skin manifestations in patients with COVID-19 has made the disease a major challenge in the world $(61,62)$. In this regard, the number of reports of skin manifestations in patients with COVID19 is constantly increasing around the world, especially in European countries (17). In the present study, which is the first systematic review and meta-analysis on COVID-19 and skin manifestations, the prevalence studies as well as case control/case series were evaluated. Accordingly, 2,621 patients with COVID-19 in prevalence studies and 54 similar patients in case control/case series were assessed for skin manifestations. A meta-analysis of prevalence studies showed that most patients with COVID-19 who had skin manifestations were from Europe $6.6 \%(1.3-12.0)$ and mainly from Italy and France. Meanwhile, Italy reported the highest number of COVID-19 patients with skin manifestations (20 cases). However, the frequency of these patients was $0.2 \%(0.0-0.5)$ in the published studies from Asian countries (China and Thailand). According to the results of the meta-analysis of included studies, the frequency of patients with
COVID-19 who also have skin manifestations is higher in Europe than in Asia. Among the reasons that can cause this difference are genetics, age, lifestyle, diet, environmental and geographical parameters of the place that patients live in, health facilities, quality of patient care in hospitals, ability to more accurately diagnose the disease, and other factors. Based on the results of current study, the most common types of skin manifestations were erythematous lesions, rash, and urticaria. On the other hand, evaluation of case reports/case series showed that out of 54 patients with COVID-19 infection, 48 had skin manifestations, most of which were related to European and American countries, respectively. The Asian and African continents ranked next. It is noteworthy to mention that at the time of performing this study there were no reports of skin manifestations in patients with COVID-19 in Oceania. According to data from case reports/case series, the number of female patients was higher than men, and the average age of all patients was 40 years. Analysis of skin manifestations in these studies, similar to those in prevalence studies, showed that erythematous lesion, rash, and urticaria were the most commonly reported skin manifestations among patients with COVID-19. According to research conducted in this field, skin manifestations such as varicella-like exanthem, petechial rash, erythematous rash, and chilblain can occur in the 
TABLE 5 | Agents used in the treatment of COVID-19 patients.

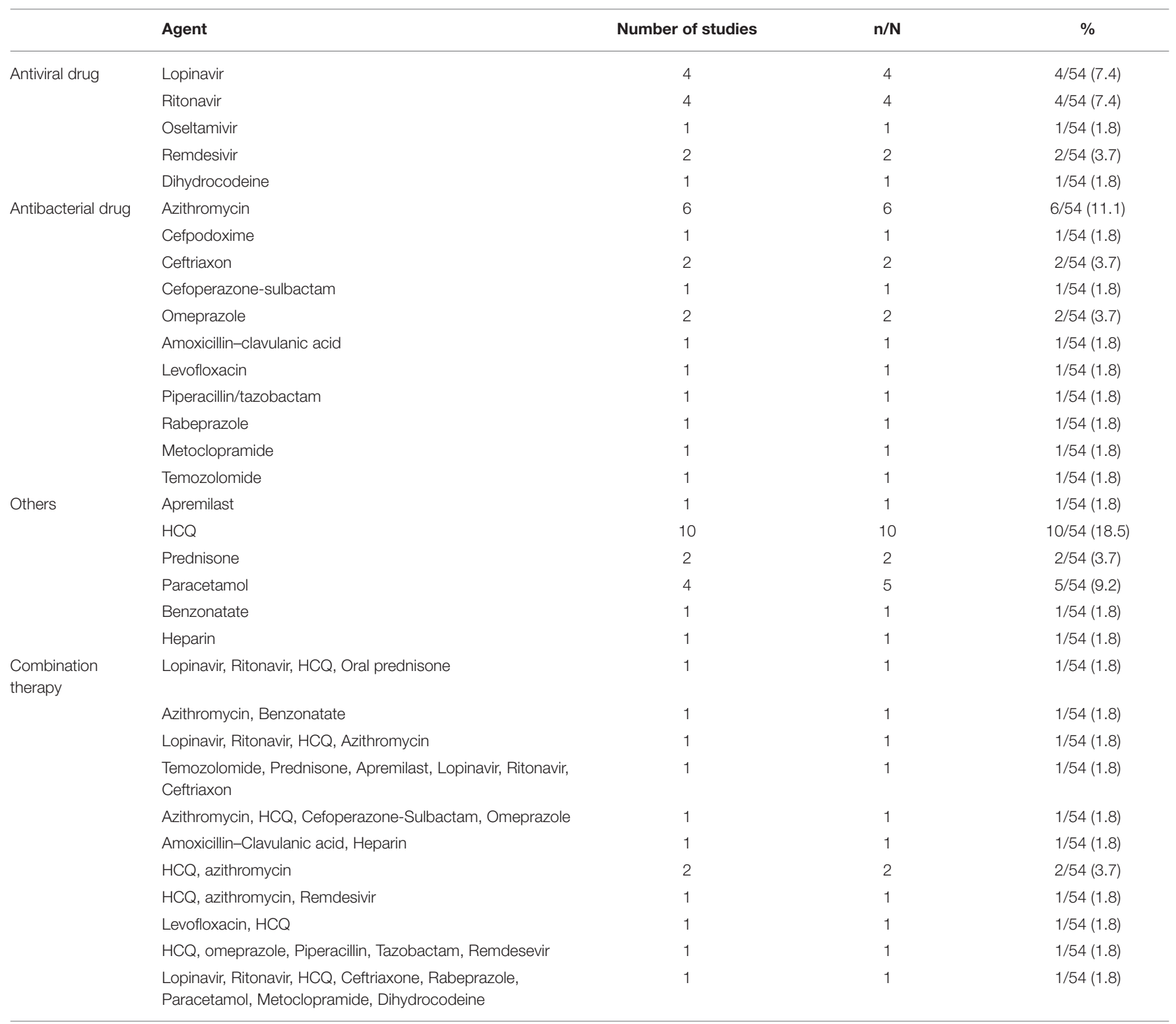

${ }^{*} n$, number of patients under treatment; $N$, the total number of patients with COVID-19.

hands, feet, and trunk, and they may sometimes be accompanied by itching and even pain. These skin manifestations can be associated with common symptoms of COVID-19 such as fever, dry cough, and myalgia. Therefore, skin manifestations can be considered as evidence with a diverse range in patients with COVID-19. According to Damme et al. (53) in Belgium, urticaria and pyrexia can be early symptoms of COVID-19, while the patient may not have any respiratory symptoms. Moreno et al. (41) in Spain showed that in a patient with COVID-19 who had fever, myalgia, weakness, cough, and diarrhea, morbilliform itchy rashes appeared on the face, neck, chest, abdomen, and other organs on the sixth day after the onset of main symptoms. The patient had no history of drug use, so skin manifestations could not be linked to drug interactions. Accordant with the results of Recalcati et al. (12) in Italy, in $20.4 \%$ of COVID19 patients, significant skin manifestations occurred. The most common skin manifestations were erythematous rash, urticaria, and vesicle, respectively, which were mainly occurred in the trunk. These people did not have any history of recent drug use leading to drug interactions. According to Guan et al. (26) in China, skin rash was observed in some patients with COVID19. It should be noted that vesicular rashes are presented in two forms: diffuse and local. The diffuse form is polymorphic, but the local form is monomorphic and only occurs in the trunk. In a study performed by Joob et al. (21) in Thailand, $2.44 \%$ of patients developed skin manifestations that were hemorrhagic and petechiae. According to a study by Landa et al. (15) in Spain, patients with COVID-19 showed purpuric manifestations 
on their fingers. They assume that these skin manifestations could be secondary symptoms of COVID-19. This theory is based on the fact that skin manifestations appear within a few weeks after the peak of infection. Sachdeva et al. (17) in Italy found that $12.5 \%$ of people with COVID-19 presented the skin manifestations at the onset of the disease. In another study by Marzano et al. (63), 22 patients with COVID-19 were evaluated. Of these, 16 patients were male. The mean age of patients was 60 years. The average duration of skin manifestations was 8 days. Most clinical manifestations in studied patients were fever, cough, weakness, coryza, dyspnea, hyposmia, hypogeusia, pharyngodynia, diarrhea, and myalgia. The death occurred in three patients. Skin manifestations in these patients were scattered in most cases and were diffuse in 6 patients. In a review by Zhao et al. (64), 44 studies were reviewed, including a total of 507 patients with COVID-19 and skin manifestations. Their results showed that $60.44 \%$ of patients were female and the mean age of patients was 49.03 (5-91) years. 488 (96.25\%) patients were in Europe. In this study, it was found that skin lesions of patients appeared 1-30 days (mean 9.92) after the onset of systemic symptoms. The maximum incubation period was 30 days and in 13 patients $(14.77 \%)$, skin lesions were observed as the first symptoms of the disease. Zhao and his colleagues observed that the skin symptoms of the patients were polymorphic, and the most common manifestations were erythema, which was mainly manifested on the trunk. Other lesions were chilblainlike lesions, urticarial-like lesions, vesicular, livedo/necrosis and petechiae, respectively. $44.77 \%$ of patients had significant pruritus in skin manifestations. The most common clinical symptoms of studied patients were fever, cough, fatigue, dyspnea, headache, gastrointestinal symptoms, and anosmia, respectively. Laboratory examination of blood samples taken from 39 patients showed that lymphocytopenia, increased CRP and LDH were the most common results, respectively. Out of 507 patients, 13 (2.56\%) died. According to a study by Tang et al. (65), of the 16 studies with 256 patients, 88 patients with COVID-19 had skin manifestations (aged between 8-84 years). Skin manifestations were mainly erythematous, urticarial, and vesicular (chicken pox-like or varicelliform). Exanthema was widely presented in the studied patients and was mainly presented on the trunk. Patients often had fever, cough, headache, fatigue, coryza, and dyspnea during the disease. The incubation period of systemic symptoms to exanthema was 2-21 days. In the study by Matar et al. (66), 56 articles including 1,020 patients were reviewed. The results indicated that the rash was the most common skin manifestations in patients with COVID-19. These rashes include erythematous maculopapular/morbilliform, urticarial/annular, vesicular/varicelliform, or petechial/purpuric. Most of the rash manifestations were in the trunk. About $70 \%$ of patients had itching. Other symptoms were burning and pain. The average days between the onset of respiratory/systemic symptoms and skin manifestations were $\sim 6.8$ days. In some cases, the rash appeared before the systemic symptoms. Therefore, skin manifestations may be considered as a potential factor in the diagnosis and isolation criteria for COVID-19 patients and help to begin the treatment as soon as possible. As stated in this study, the most reported clinical symptoms were fever, cough, dyspepsia, and respiratory problems; and the least ones were anorexia, pain, malaise, dysgeusia, abdominal discomfort, hypoxemia, constipation, tachycardia, chills, anosmia, ageusia, insomnia, transient blurred vision, confusion, and coryza. In a study by Casas et al. (14) in Spain, the clinical manifestations were cough, dyspnea, fever, asthenia, headache, nausea and vomiting, diarrhea, and pneumonia. Another parameter that was evaluated in this study was comorbidities. Based on the results of our study, diabetes, obesity, hypertension, and chronic renal failure were the most common comorbidities in COVID-19 patients with skin manifestations. These underlying diseases were also reported in a study by McMichael et al. (67) in the United States. Among 81 COVID-19 patients admitted to hospital, $69.1 \%$ had hypertension, $43.2 \%$ had renal disease, and $37.0 \%$ had diabetes.

CT scan is one of the diagnostic methods with optimal sensitivity (68). This method can be very helpful in diagnosing COVID-19 patients in order to determine the involvement of the lungs and disease progression. However, this method may not detect lung involvement in the early stages of the disease and may not accurately diagnose the presence of COVID-19 in the patient (69). Based on the results of current study, the findings of CT scan in most COVID-19 patients with skin manifestations have been reported as bilateral patchy shadowing (bilateral interstitial abnormalities and bilateral airspace opacities). However, in some cases, patients had normal CT scans. In other words, skin manifestations appeared in some COVID-19 patients before lung involvement. Other manifestations such as consolidations, thickening of lobar fissures, adjacent pleura, paving patterns, mediastinal lymphadenopathies, and hilar lymphadenopathies were not reported in the patients.

Laboratory findings evaluation revealed that elevated CRP, thrombocytopenia, and increased D-dimer were among the most abnormal laboratory changes. As specified by Zhang et al. (70), this virus increases $\mathrm{D}$-dimer and destroys fibrinogen products leading to acro-ischemia, which is associated with cyanosis of the fingers. Numerous studies have also shown an increase in Ddimer in laboratory findings (71-73). This laboratory evidence is likely to be related to the severity of the disease and skin involvement. However, it is not possible to speak for sure about the exact cause and origin of these laboratory changes in the patients. As mentioned in a study by Zhang et al. (70) in China, an increase in CRP has been reported in $92.14 \%$ of 140 COVID19 patients. In a study by Yang et al. (74) in China, of the 1,476 COVID-19 patients, $20.7 \%$ reported thrombocytopenia. Numerous other studies have also reported an increase in thrombocytopenia in COVID-19 patients (75-77). Despite many efforts to control COVID-19, the disease continues to be a major challenge for the global community and a threat to public health. Although much investigate has been made to treat COVID-19 worldwide, there is still no definitive cure. However, supportive therapies such as antipyretics for fever, oxygen therapy for respiratory distress, rest at home, and intake of fluids in the early stages of the disease can be effective $(78,79)$. In the basis of analysis performed in current study, the most antiviral drugs prescribed to patients included Lopinavir, Ritonavir (as HIV protease inhibitors), and Remdesivir. According to various studies, Lopinavir and Ritonavir have been shown to improve 
clinical manifestations and reduce the infection rate of viruses $(80,81)$. Limited clinical information suggest that Remdesivir may have potential activity against COVID-19. Examination of studies showed that in addition to antiviral drugs, azithromycin and HCQ were among the most widely used drugs in the treatment of patients. Different treatment regimens have been used in numerous studies, but only one treatment regimen (azithromycin and HCQ) has been mostly used. Unfortunately, there is not enough information about the effectiveness of the drugs listed in Table 5 and it is not possible to determine the effectiveness of these drugs in treating patients. However, based on the reported results, of the 48 patients in the case reports/case series, only one case resulted in death, which was just treated with HCQ. In general, effective control of infection along with the development of efficient drugs in the treatment of COVID-19 is of great importance for tremendous success in the fight against the disease and reducing mortality. Therefore, it is important to follow infection control protocols in health care. Lack of preventive health measures, insufficient training of employees and lack of infection control programs in the hospitals can play a significant role in increasing the number of COVID19 patients and possibly in the prevalence of skin diseases and increased mortality rates in these patients. Finally, it is important to mention the limitations of the study. First, in our study, only published articles were reviewed. Second, some of the published reports lacked the inclusion criteria of this study. Third, because there is not enough information in many countries, we were not able to fully demonstrate the prevalence of skin manifestations in COVID-19 patients worldwide. Many COVID-19 patients with skin manifestations may not have been hospitalized and most of them could have been treated at home. This can also affect our inability to fully demonstrate skin manifestations in people with COVID-19 around the world. Fourth, some of the articles did not have sufficient data to analyze the factors mentioned in this study, such as laboratory findings, comorbidities, CT scan results, and the outcome. Fifth: Another limitation of this study was that many articles did not publish sufficient data to assess the side effects of drugs or the side effects of infection. As a result, we have not been able to examine them and discuss in detail the mechanisms of skin manifestations in patients with COVID-19.

\section{REFERENCES}

1. Zhou P, Yang X-L, Wang X-G, Hu B, Zhang L, Zhang W, et al. A pneumonia outbreak associated with a new coronavirus of probable bat origin. Nature. (2020) 579:270-3. doi: 10.1038/s41586-020-2012-7

2. Lu Q, Shi Y. Coronavirus disease (COVID-19) and neonate: what neonatologist need to know. J Med Virol. (2020) 92:5647. doi: $10.1002 /$ jmv. 25740

3. Frutos R, Lopez Roig M, Serra-Cobo J, Devaux CA. COVID-19: the conjunction of events leading to the coronavirus pandemic and lessons to learn for future threats. Front Med. (2020) 7:223. doi: 10.3389/fmed.2020.00223

4. Zhang $\mathrm{H}$, Chen $\mathrm{R}$, Chen J, Chen B. COVID-19 transmission within a family cluster in Yancheng, China. Front Med. (2020) 7:387. doi: 10.3389/fmed.2020.00387

5. Repici A, Maselli R, Colombo M, Gabbiadini R, Spadaccini M, Anderloni A, et al. Coronavirus (COVID-19) outbreak: what the

\section{CONCLUSION}

According to the results of included studies, skin manifestations in COVID-19 patients are very diverse and can occur at the beginning of the disease or after antibiotic treatment. Based on our results, skin manifestations including erythematous lesions, rash, and urticaria were the most commonly reported among patients with COVID-19. Identifying these skin manifestations can be a quick way to diagnose some COVID-19 patients. As a result, the importance of this issue is to help stop the spread of COVID-19 and protect other people. In addition to the importance of the side effects of COVID-19, the importance of drug interactions during supportive therapy should also be considered. As a final conclusion, physicians can consider skin manifestations as important clinical features in the diagnosis of patients with COVID-19. However, further study and investigation is needed to confirm and explain an understanding of COVID-19-related skin manifestations.

\section{DATA AVAILABILITY STATEMENT}

All datasets generated for this study are included in the article/supplementary material.

\section{AUTHOR CONTRIBUTIONS}

MD and FS designed the study. $\mathrm{BH}$ and $\mathrm{MG}$ conducted the search strategy. FS, SY, PO, MN, and MB performed the data extraction. $\mathrm{MD}$ and $\mathrm{BH}$ wrote and edited the manuscript. MD carried out the statistical analysis. MD and SS assumed overall responsibility for the accuracy and integrity of the manuscript. All authors contributed to the article and approved the submitted version.

\section{ACKNOWLEDGMENTS}

The authors would like to thank Dr. Reza Robati (dermatologist), Department of Dermatology at Shahid Beheshti University of Medical Sciences, Tehran, Iran, for his sincere assistance and efforts to make this project happen.

department of endoscopy should know. Gastrointest Endosc. (2020) 92:192-7. doi: 10.1016/j.gie.2020.03.019

6. Sernicola A, Alaibac M. How to deal with post-viral cutaneous eruptions in the era of coronavirus infection. Front Med. (2020) 7:224. doi: 10.3389/fmed.2020.00224

7. Larsen JR, Martin MR, Martin JD, Kuhn P, Hicks JB. Modeling the onset of symptoms of COVID-19. Frontiers in Public Health. (2020) 8:473. doi: 10.3389/fpubh.2020.00473

8. Guo Y-R, Cao Q-D, Hong Z-S, Tan Y-Y, Chen S-D, Jin H-J, et al. The origin, transmission and clinical therapies on coronavirus disease 2019 (COVID-19) outbreak-an update on the status. Mil Med Res. (2020) 7:11. doi: 10.1186/s40779-020-00240-0

9. Lei S, Jiang $\mathrm{F}$, Su W, Chen C, Chen J, Mei W, et al. Clinical characteristics and outcomes of patients undergoing surgeries during the incubation period of COVID-19 infection. EClinicalMedicine. (2020) 21:100331. doi: 10.1016/j.eclinm.2020. 100331 
10. Rodriguez-Morales AJ, Cardona-Ospina JA, Gutiérrez-Ocampo E, VillamizarPeña R, Holguin-Rivera Y, Escalera-Antezana JP, et al. Clinical, laboratory and imaging features of COVID-19: a systematic review and meta-analysis. Travel Med Infect Dis. (2020) 34:101623. doi: 10.1016/j.tmaid.2020.101623

11. Lechien JR, Chiesa-Estomba CM, de Siati DR, Horoi M, Le Bon SD, Rodriguez A, et al. Olfactory and gustatory dysfunctions as a clinical presentation of mild-to-moderate forms of the coronavirus disease (COVID-19): a multicenter European study. Eur Arch Otorhinolaryngol. (2020) 277:225161. doi: 10.1007/s00405-020-05965-1

12. Recalcati S. Cutaneous manifestations in COVID-19: a first perspective. J Eur Acad Dermatol Venereol. (2020) 34:e212-3. doi: 10.1111/jdv.16387

13. Kaur I, Sharma A, Jakhar D, Das A, Aradhya SS, Sharma R, et al. Coronavirus disease (COVID-19): an updated review based on current knowledge and existing literature for dermatologists. Dermatol Ther. (2020) 33:e13677. doi: 10.1111/dth.13677

14. Galván Casas C, Català A, Carretero Hernández G, Rodríguez-Jiménez P, Fernández Nieto D, Rodríguez-Villa Lario A, et al. Classification of the cutaneous manifestations of COVID-19: a rapid prospective nationwide consensus study in Spain with 375 cases. Br J Dermatol. (2020) 183:717. doi: 10.1111/bjd.19163

15. Landa N, Mendieta-Eckert M, Fonda-Pascual P, Aguirre T. Chilblain-like lesions on feet and hands during the COVID-19 pandemic. Int J Dermatol. (2020) 59:739-43. doi: 10.1111/ijd.14937

16. Colonna C, Monzani NA, Rocchi A, Gianotti R, Boggio F, Gelmetti C. Chilblains-like lesions in children following suspected Covid-19 infection. Pediatr Dermatol. (2020) 37:437-40. doi: 10.1111/pde.14210

17. Sachdeva M, Gianotti R, Shah M, Lucia B, Tosi D, Veraldi S, et al. Cutaneous manifestations of COVID-19: report of three cases and a review of literature. J Dermatol Sci. (2020) 98:75-81. doi: 10.1016/j.jdermsci.2020.04.011

18. Suchonwanit P, Leerunyakul K, Kositkuljorn C. Cutaneous manifestations in COVID-19: lessons learned from current evidence. J Am Acad Dermatol. (2020) 83:e57-60. doi: 10.1016/j.jaad.2020.04.094

19. Mantel N, Haenszel W. Statistical aspects of the analysis of data from retrospective studies of disease. J Natl Cancer Inst. (1959) 22:719-48.

20. Bouaziz J, Duong T, Jachiet M, Velter C, Lestang P, Cassius C, et al. Vascular skin symptoms in COVID-19: a french observational study. J Eur Acad Dermatol Venereol. (2020) 34:e451-2. doi: 10.1111/jdv.16544

21. Joob B, Wiwanitkit V. Hemorrhagic problem among the patients with COVID-19: clinical summary of 41 thai infected patients. Clin Appl Thromb Hemost. (2020) 26:1076029620918308. doi: 10.1177/1076029620918308

22. Joob B, Wiwanitkit V. COVID-19 can present with a rash and be mistaken for Dengue. J Am Acad Dermatol. (2020) 82:e177. doi: 10.1016/j.jaad.2020.03.036

23. Tammaro A, Adebanjo G, Parisella F, Pezzuto A, Rello J. Cutaneous manifestations in COVID-19: the experiences of Barcelona and Rome. J Eur Acad Dermatol Venereol. (2020) 34:e306-7. doi: 10.1111/jdv.16530

24. Zhang J-j, Dong X, Cao Y-y, Yuan Y-d, Yang Y-b, Yan Y-q, et al. Clinical characteristics of 140 patients infected with SARS-CoV-2 in Wuhan, China. Allergy. (2020) 75:1730-41. doi: 10.1111/all.14238

25. Million M, Lagier J-C, Gautret P, Colson P, Fournier P-E, Amrane S, et al. Fulllength title: early treatment of COVID-19 patients with hydroxychloroquine and azithromycin: a retrospective analysis of 1061 cases in Marseille, France. Travel Med Infect Dis. (2020) 35:101738. doi: 10.1016/j.tmaid.2020.101738

26. Guan W-j, Ni Z-y, Hu Y, Liang W-h, Ou C-q, He J-x, et al. Clinical characteristics of coronavirus disease 2019 in China. N Engl J Med. (2020) 382:1708-20. doi: 10.1056/NEJMoa2002032

27. Ehsani AH, Nasimi M, Bigdelo Z. Pityriasis rosea as a cutaneous manifestation of COVID-19 infection. J Eur Acad Dermatol Venereol. (2020) 34:e4367. doi: $10.1111 /$ jdv.16579

28. Ma J, Xia P, Zhou Y, Liu Z, Zhou X, Wang J, et al. Potential effect of blood purification therapy in reducing cytokine storm as a late complication of severe COVID-19. Clin Immunol. (2020) 214:108408. doi: 10.1016/j.clim.2020.108408

29. Qian S-Z, Pan J-Y. COVID-19 with limb ischemic necrosis. J Cardiothorac Vasc Anesth. (2020) 34:2846-7. doi: 10.1053/j.jvca.2020.03.063

30. Lu S, Lin J, Zhang Z, Xiao L, Jiang Z, Chen J, et al. Alert for non-respiratory symptoms of coronavirus disease 2019 (COVID-19) patients in epidemic period: a case report of familial cluster with three asymptomatic COVID-19 patients. J Med Virol. (2020) 1-4. doi: 10.1002/jmv.25776
31. Alramthan A, Aldaraji W. A case of COVID-19 presenting in clinical picture resembling chilblains disease: first report from the middle East. Clin Exp Dermatol. (2020) 45:746-8. doi: 10.1111/ced.14243

32. Gunawan C, Widysanto A. Urticarial eruption in coronavirus disease 2019 (COVID-19) infection: a case report in Tangerang, Indonesia. J Eur Acad Dermatol Venereol. (2020). doi: 10.1111/jdv.16622

33. Henry D, Ackerman M, Sancelme E, Finon A, Esteve E. Urticarial eruption in COVID-19 infection. J Eur Acad Dermatol Venereol. (2020) 34:e3723. doi: $10.1111 /$ jdv.16472

34. Mahé A, Birckel E, Krieger S, Merklen C, Bottlaender L. A distinctive skin rash associated with Coronavirus Disease 2019? J Eur Acad Dermatol Venereol. (2020) 34:e246-7. doi: 10.1111/jdv.16471

35. Zulfiqar A-A, Lorenzo-Villalba $\mathrm{N}$, Hassler $\mathrm{P}$, Andrès E. Immune thrombocytopenic purpura in a patient with COVID-19. N Engl J Med. (2020) 382:e43. doi: 10.1056/NEJMc2010472

36. Ahouach B, Harant S, Ullmer A, Martres P, Bégon E, Blum L, et al. Cutaneous lesions in a patient with COVID-19: are they related? Br J Dermatol. (2020) 183:e31. doi: 10.1111/bjd.19168

37. Chaux-Bodard A-G, Deneuve S, Desoutter A. Oral manifestation of Covid-19 as an inaugural symptom? J Oral Med Oral Surg. (2020) 26:18. doi: $10.1051 / \mathrm{mbcb} / 2020011$

38. Amatore F, Macagno N, Mailhe M, Demarez B, Gaudy-Marqueste C, Grob J, et al. SARS-CoV-2 infection presenting as a febrile rash. J Eur Acad Dermatol Venereol. (2020) 34:e304-6. doi: 10.1111/jdv.16528

39. Sanchez A, Sohier P, Benghanem S, L'Honneur A-S, Rozenberg F, Dupin $\mathrm{N}$, et al. Digitate Papulosquamous Eruption Associated With Severe Acute Respiratory Syndrome Coronavirus 2 Infection. JAMA Dermatol. (2020) 156:819-820. doi: 10.1001/jamadermatol.2020.1704

40. Quintana-Castanedo L, Feito-Rodríguez M, Valero-López I, ChiloechesFernández C, Sendagorta-Cudós E, Herranz-Pinto P. Urticarial exanthem as early diagnostic clue for COVID-19 infection. JAAD Case Rep. (2020) 6:498-9. doi: 10.1016/j.jdcr.2020.04.026

41. Avellana Moreno R, Villa E, Avellana Moreno V, Estela Villa C, Aparicio M, Fontanella A. Cutaneous manifestation of COVID-19 in images: a case report. J Eur Acad Dermatol Venereol. (2020) 34:e307-9. doi: 10.1111/jdv.16531

42. Estébanez A, Pérez-Santiago L, Silva E, Guillen-Climent S, García-Vázquez A, Ramón MD. Cutaneous manifestations in COVID-19: a new contribution. J Eur Acad Dermatol Venereol. (2020) 34:e250-1. doi: 10.1111/jdv.16474

43. Diaz-Guimaraens B, Dominguez-Santas M, Suarez-Valle A, Pindado-Ortega C, Selda-Enriquez G, Bea-Ardebol S, et al. Petechial skin rash associated with severe acute respiratory syndrome coronavirus 2 infection. JAMA Dermatol. (2020) 156:820-2. doi: 10.1001/jamadermatol.2020.1741

44. Morey-Olivé M, Espiau M, Mercadal-Hally M, Lera-Carballo E, GarcíaPatos V, editors. Cutaneous manifestations in the current pandemic of coronavirus infection disease (COVID 2019). An Pediatr. (2020) 92:3745. doi: 10.1016/j.anpede.2020.04.002

45. Robustelli Test E, Vezzoli P, Carugno A, Raponi F, Gianatti A, Rongioletti F, et al. Acute generalized exanthematous pustulosis with erythema multiformelike lesions in a COVID-19 woman. J Eur Acad Dermatol Venereol. (2020) 34:e457-9. doi: 10.1111/jdv.16613

46. Mugheddu C, Pizzatti L, Sanna S, Atzori L, Rongioletti F. COVID19 pulmonary infection in erythrodermic psoriatic patient with oligodendroglioma: safety and compatibility of apremilast with critical intensive care management. J Eur Acad Dermatol Venereol. (2020) 34:e376-8. doi: 10.1111/jdv.16625

47. Locatelli A, Robustelli Test E, Vezzoli P, Carugno A, Moggio E, Consonni L, et al. Histologic features of long lasting chilblain-like lesions in a pediatric COVID-19 patient. J Eur Acad Dermatol Venereol. (2020) 34:e3658. doi: $10.1111 /$ jdv.16617

48. Zengarini C, Orioni G, Cascavilla A, Horna Solera C, Fulgaro C, Misciali C, et al. Histological pattern in Covid-19 induced viral rash. J Eur Acad Dermatol Venereol. (2020) 34:e453-4. doi: 10.1111/jdv.16569

49. Paolino G, Canti V, Raffaele MS, Rovere QP, Candiani M, Pasi F. Diffuse cutaneous manifestation in a new mother with COVID-19 (SARS-Cov-2). Int J Dermatol. (2020) 59:874-5. doi: 10.1111/ijd.14919

50. Genovese G, Colonna C, Marzano AV. Varicella-like exanthem associated with COVID-19 in an 8-year-old girl: a diagnostic clue? Pediatr Dermatol. (2020) 37:435-6. doi: 10.1111/pde.14201 
51. Gianotti R, Zerbi P, Dodiuk-Gad RP. Clinical and histopathological study of skin dermatoses in patients affected by COVID-19 infection in the Northern part of Italy. J Dermatol Sci. (2020) 98:141-3. doi: 10.1016/j.jdermsci.2020.04.007

52. Kolivras A, Dehavay F, Delplace D, Feoli F, Meiers I, Milone L, et al. Coronavirus (COVID-19) infection-induced chilblains: a case report with histopathologic findings. JAAD Case Rep. (2020) 6:48992. doi: 10.1016/j.jdcr.2020.04.011

53. van Damme C, Berlingin E, Saussez S, Accaputo O. Acute urticaria with pyrexia as the first manifestations of a COVID-19 infection. J Eur Acad Dermatol Venereol. (2020) 34:e300-1. doi: 10.1111/jdv.16523

54. Hoehl S, Rabenau H, Berger A, Kortenbusch M, Cinatl J, Bojkova D, et al. Evidence of SARS-CoV-2 infection in returning travelers from Wuhan, China. N Engl J Med. (2020) 382:1278-80. doi: 10.1056/NEJMc2001899

55. Najarian DJ. Morbilliform exanthem associated with COVID-19. JAAD Case Rep. (2020) 6:493-4. doi: 10.1016/j.jdcr.2020.04.015

56. Magro C, Mulvey JJ, Berlin D, Nuovo G, Salvatore S, Harp J, et al. Complement associated microvascular injury and thrombosis in the pathogenesis of severe COVID-19 infection: a report of five cases. Transl Res. (2020) 220:113. doi: 10.1016/j.trsl.2020.04.007

57. Manalo IF, Smith MK, Cheeley J, Jacobs R. Reply: a dermatologic manifestation of COVID-19: transient livedo reticularis. J Am Acad Dermatol. (2020) 83:e157. doi: 10.1016/j.jaad.2020.04.018

58. Hunt M, Koziatek C. A case of COVID-19 pneumonia in a young male with full body rash as a presenting symptom. Clin Pract Cases Emerg Med. (2020) 4:219-21. doi: 10.5811/cpcem.2020.3.47349

59. Janah H, Zinebi A, Elbenaye J. Atypical erythema multiforme palmar plaques lesions due to Sars-Cov-2. J Eur Acad Dermatol Venereol. (2020) 34:e3735. doi: $10.1111 /$ jdv.16623

60. Lee CY-P, Lin RT, Renia L, Ng LF. Serological approaches for COVID-19: epidemiologic perspective on surveillance and control. Front Immunol. (2020) 11:879. doi: 10.3389/fimmu.2020.00879

61. Zheng Y, Lai W. Dermatology staff participate in fight against Covid-19 in China. J Eur Acad Dermatol Venereol. (2020) 34:e210-1. doi: $10.1111 /$ jdv. 16390

62. Wollina U, Karadag AS, Rowland-Payne C, Chiriac A, Lotti T. Cutaneous signs in COVID-19 patients: a review. Dermatol Ther. (2020) 33:e13549. doi: 10.1111/dth.13549

63. Marzano AV, Genovese G, Fabbrocini G, Pigatto P, Monfrecola G, Piraccini BM, et al. Varicella-like exanthem as a specific COVID-19-associated skin manifestation: multicenter case series of 22 patients. J Am Acad Dermatol. (2020) 83:280-5. doi: 10.1016/j.jaad.2020.04.044

64. Zhao Q, Fang X, Pang Z, Zhang B, Liu H, Zhang F. COVID-19 and cutaneous manifestations: a systematic review. J Eur Acad Dermatol Venereol. (2020). doi: 10.1111/jdv.16778

65. Tang K, Wang Y, Zhang H, Zheng Q, Fang R, Sun Q. Cutaneous manifestations of the coronavirus disease 2019 (COVID-19): a brief review. Dermatol Ther. (2020) 33:e13528. doi: 10.1111/dth.13528

66. Matar S, Oulès B, Sohier P, Chosidow O, Beylot-Barry M, Dupin N, et al. Cutaneous manifestations in SARS-CoV-2 infection (COVID-19): a French experience and a systematic review of the literature. J Eur Acad Dermatol Venereol. (2020). doi: 10.1111/jdv.16775

67. McMichael TM. COVID-19 in a long-term care facility-King County, Washington, February 27-March 9, 2020. MMWR Morb Mortal Wkly Rep. (2020) 69:339-42. doi: 10.15585/mmwr.mm6912e1

68. Radpour A, Bahrami-Motlagh H, Taaghi MT, Sedaghat A, Karimi MA, Hekmatnia A, et al. COVID-19 evaluation by low-dose high resolution CT scans protocol. Acad Radiol. (2020) 27:901. doi: 10.1016/j.acra.2020.04.016
69. Chate RC, Fonseca EKUN, Passos RBD, Teles GBdS, Shoji H, Szarf G. Presentation of pulmonary infection on CT in COVID-19: initial experience in Brazil. J Bras Pneumol. (2020) 46:e20200121. doi: 10.36416/1806-3756/e20200121

70. Zhang Y, Cao W, Xiao M, Li Y, Yang Y, Zhao J, et al. Clinical and coagulation characteristics in 7 patients with critical COVID-2019 pneumonia and acro-ischemia. Zhonghua Xue Ye Xue Za Zhi. (2020) 41:3027. doi: $10.3760 / \mathrm{cma}$.j.issn.0253-2727.2020.0006

71. Léonard-Lorant I, Delabranche X, Séverac F, Helms J, Pauzet C, Collange O, et al. Acute pulmonary embolism in patients with COVID-19 at CT angiography and relationship to d-Dimer levels. Radiology. (2020) 296:E18991. doi: 10.1148/radiol.2020201561

72. Shah S, Shah K, Patel SB, Patel FS, Osman M, Velagapudi P, et al. Elevated D-dimer levels are associated with increased risk of mortality in COVID-19: a systematic review and meta-analysis. medRxiv. (2020). doi: 10.1101/2020.04.29.20085407

73. Levi M, Thachil J, Iba T, Levy JH. Coagulation abnormalities and thrombosis in patients with COVID-19. Lancet Haematol. (2020) 7:e43840. doi: 10.1016/S2352-3026(20)30145-9

74. Yang $\mathrm{X}$, Yang Q, Wang $\mathrm{Y}, \mathrm{Wu} \mathrm{Y}, \mathrm{Xu} J$, Yu Y, et al. Thrombocytopenia and its association with mortality in patients with COVID-19. J Thromb Haemost. (2020) 18:1469-72. doi: 10.1111/jth.14848

75. Xu P, Zhou Q, Xu J. Mechanism of thrombocytopenia in COVID-19 patients. Ann Hematol. (2020) 99:1205-8. doi: 10.1007/s00277-020-04019-0

76. Ahmed MZ, Khakwani M, Venkatadasari I, Horgan C, Giles H, Jobanputra S, et al. Thrombocytopenia as an initial manifestation of Covid-19; case series and literature review. Br J Haematol. (2020) 189:10578. doi: 10.1111/bjh.16769

77. Lippi G, Plebani M, Henry BM. Thrombocytopenia is associated with severe coronavirus disease 2019 (COVID-19) infections: a meta-analysis. Clin Chim Acta. (2020) 506:145-8. doi: 10.1016/j.cca.2020.03.022

78. Tobaiqy M, Qashqary M, Al-Dahery S, Mujallad A, Hershan AA, Kamal MA, et al. Therapeutic management of COVID-19 patients: a systematic review. Infect Prev Pract. (2020) 2:100061. doi: 10.1101/2020.04.02.20051029

79. Bajwah S, Wilcock A, Towers R, Costantini M, Bausewein C, Simon ST, et al. Managing the supportive care needs of those affected by COVID-19. Eur Respir Soc. (2020) 55:2000815. doi: 10.1183/13993003.00815-2020

80. Hung IF-N, Lung K-C, Tso EY-K, Liu R, Chung TW-H, Chu M-Y, et al. Triple combination of interferon beta- $1 \mathrm{~b}$, lopinavir-ritonavir, and ribavirin in the treatment of patients admitted to hospital with COVID19: an open-label, randomised, phase 2 trial. Lancet. (2020) 395:1695704. doi: 10.1016/S0140-6736(20)31042-4

81. Kaplan SS, Hicks CB. Safety and antiviral activity of lopinavir/ritonavirbased therapy in human immunodeficiency virus type 1 (HIV-1) infection. J Antimicrob Chemother. (2005) 56:273-6. doi: 10.1093/jac/ dki209

Conflict of Interest: The authors declare that the research was conducted in the absence of any commercial or financial relationships that could be construed as a potential conflict of interest.

Copyright (c) 2020 Sameni, Hajikhani, Yaslianifard, Goudarzi, Owlia, Nasiri, Shokouhi, Bakhtiyari and Dadashi. This is an open-access article distributed under the terms of the Creative Commons Attribution License (CC BY). The use, distribution or reproduction in other forums is permitted, provided the original author(s) and the copyright owner(s) are credited and that the original publication in this journal is cited, in accordance with accepted academic practice. No use, distribution or reproduction is permitted which does not comply with these terms. 